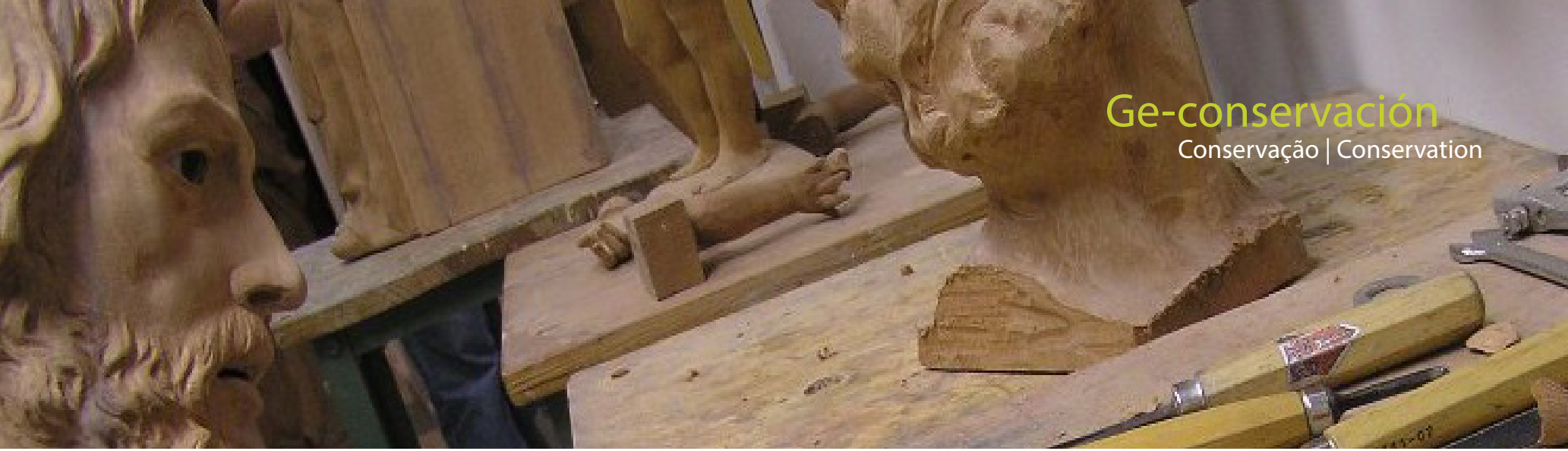

\title{
Patrimonio con el Sello Europeo: posibilidades para la Semana Santa sevillana
}

\author{
Pablo Travasos Hernández
}

Resumen: En este artículo se analizan las posibilidades de conservación y salvaguarda que podría ofrecer la figura internacional Patrimonio con el Sello Europeo a la Semana Santa sevillana. Para ello se estudia su valor histórico-artístico y cultural desde un punto de vista continental, así como la vigencia y contemporaneidad de su dimensión material e inmaterial cuya salvaguarda continua siendo todo un reto para conservadores y restauradores.

Palabras clave: patrimonio eclesiástico Europa, bienes culturales, conservación, inmaterial, interdisciplinar

\section{European Heritage Label: Possibilities for the Holy Week in Sevilla}

Abstract: This article discusses the possibilities of conservation and safeguard that might offer the international figure European Heritage Label to the Holy Week in Seville. For it is studied his historical-artistic and cultural value from a continental point of view, as well as the validity and trendiness of his material and immaterial dimension whose continued safeguarding feel a challenge for curators and conservators.

Key words: religious heritage, Europe, cultural assets, conservation, immaterial, interdisciplinary

\section{Património com o Selp Europeu: Possibilidades da Semana Santa Sevilhana}

Resumo: Este artigo analisa as possibilidades de conservação e de salvaguarda que o Selo Europeu poderia oferecer à Semana Santa sevilhana. Tendo esse objetivo em mente, estuda-se neste momento o seu valor histórico-artistico e cultural desde uma perspetiva continental, assim como a vigência e contemporaneidade da sua dimensão material e imaterial.

Palavras-chave: Património eclesiástico, Europa, bens culturais, conservação, imaterial, interdisciplinar

\section{Introducción}

Para poder hablar de la Semana Santa hispalense, como ocurre en otros casos alrededor de la geografía nacional española, debemos tener en cuenta que nos enfrentamos a un microcosmos constituido por una serie de elementos que transcienden su realidad física para integrarse en la definición del carácter de un pueblo. Desde la teatralidad de la fiesta que adquiere todo su sentido durante el barroco y se mantiene a día de hoy a través de la ciudad como un escenario urbano; hasta la consideración administrativa actual que define su nivel de protección y la sitúa como un motor económico a través del turismo de masas, hemos de intentar comprender en su totalidad un acontecimiento cuyos cimientos se encuentran en lo más profundo de la historia y el patrimonio de la provincia.

El carácter diverso, complejo, profundo y polisémico de la festividad exige un profundo y necesario esfuerzo interdisciplinar para perseguir su salvaguarda. A la labor de etnólogos, antropólogos o historiadores, se han sumado con fuerza las tareas de conservación y restauración situando a las piezas protagonistas bajo la lente del microscopio. Con la aplicación de estos procedimientos 
científicos se ha conseguido apreciar cómo el estado de los bienes materiales que conforman este mosaico cultural presenta profundas alteraciones fruto de intervenciones $y$ procedimientos ya superados en teoría.

Las aportaciones generadas por las diferentes investigaciones de cada una de estas materias han permitido generar un campo de estudio casi inabarcable, creando nuevas vías de análisis cada vez más concretas y exhaustivas ante el caudal cultural emanado de una manifestación popular vertebrada y orquestada por el pueblo a lo largo de los siglos. $Y$ es que no podemos olvidar que, como vienen defendiendo los etnólogos o los antropólogos desde hace años, es la sociedad la encargada de aceptar, transformar o suprimir de su vida cualquier manifestación emanada de su identidad colectiva (Llop i Bayo 2009: 133) [figura 1].

Partiendo de esta base, al observar con perspectiva la estela originada por las averiguaciones relacionadas con la Semana Santa es como alcanzamos a vislumbrar verdaderamente su valor cultural de un modo tangible y completo. Concibiendo alternativas y enfoques globales, capaces de asimilar ideas y conceptos engendrados en la esencia multidisciplinar de la fiesta para interrelacionarlos, aspiramos a alcanzar un mayor conocimiento de la misma $y$, en consecuencia, mejorar las herramientas y medidas disponibles para su correcta conservación.

Uno de los mayores hitos de investigación interdisciplinar llevados a cabo en Andalucía para la puesta en valor de su patrimonio en relación al paisaje internacional, sería el proyecto Andalucía Barroca en el año 2007'. Dejando a un lado las diferentes exposiciones o itinerarios creados especialmente para la ocasión, los apartados que configuraron el Congreso Internacional Andalucía Barroca sirven de ejemplo para ilustrar el amplísimo abanico de posibilidades que ofrece el papel de la comunidad en la Historia, en un periodo tan fundamental para comprender la idiosincrasia andaluza y, en consecuencia, la formación de su actitud vital y social: I. Arte, Arquitectura y Urbanismo, II. Historia Demográfica, Económica y Social, III. Literatura, Música y Fiesta, IV. Ciencia, Filosofía y Religiosidad. Unos apartados sobre los que, a día de hoy, se sigue sustentando en gran medida una de las mayores fiestas barrocas que se han conservado y refundado en nuestro tiempo: la Semana Santa sevillana. Con empresas como Andalucía Barroca nos adentramos en el dilatado mundo de expresiones populares que van del rezo a lo culinario, recorriendo un sinfín de actividades que surgen en torno a la representación teatral de la Pasión y que definirán el carácter de todo un pueblo transmitido de generación en generación.

A pesar de que el evento, junto a otras muchas festividades nacionales, contenga evidencias más que refutadas de su validez como Patrimonio Cultural Inmaterial de la Humanidad (Carrera 2009: 20), nos encontramos con la compleja situación de afrontar la validez de los homenajes religiosos en un contexto de globalización que aboga por valores universales ajenos a cuestiones confesionales. La dramatización de la Pasión puede suscitar, aún en pleno siglo XXI, acalorados debates incluso en los lugares donde las romerías o procesiones tienen mayor tradición, encontrándonos con la paradójica circunstancia de que la propia vitalidad del ceremonial puede suponer su mayor factor de deterioro. Enfrentarnos a su conservación es, en consecuencia, una compleja tarea.

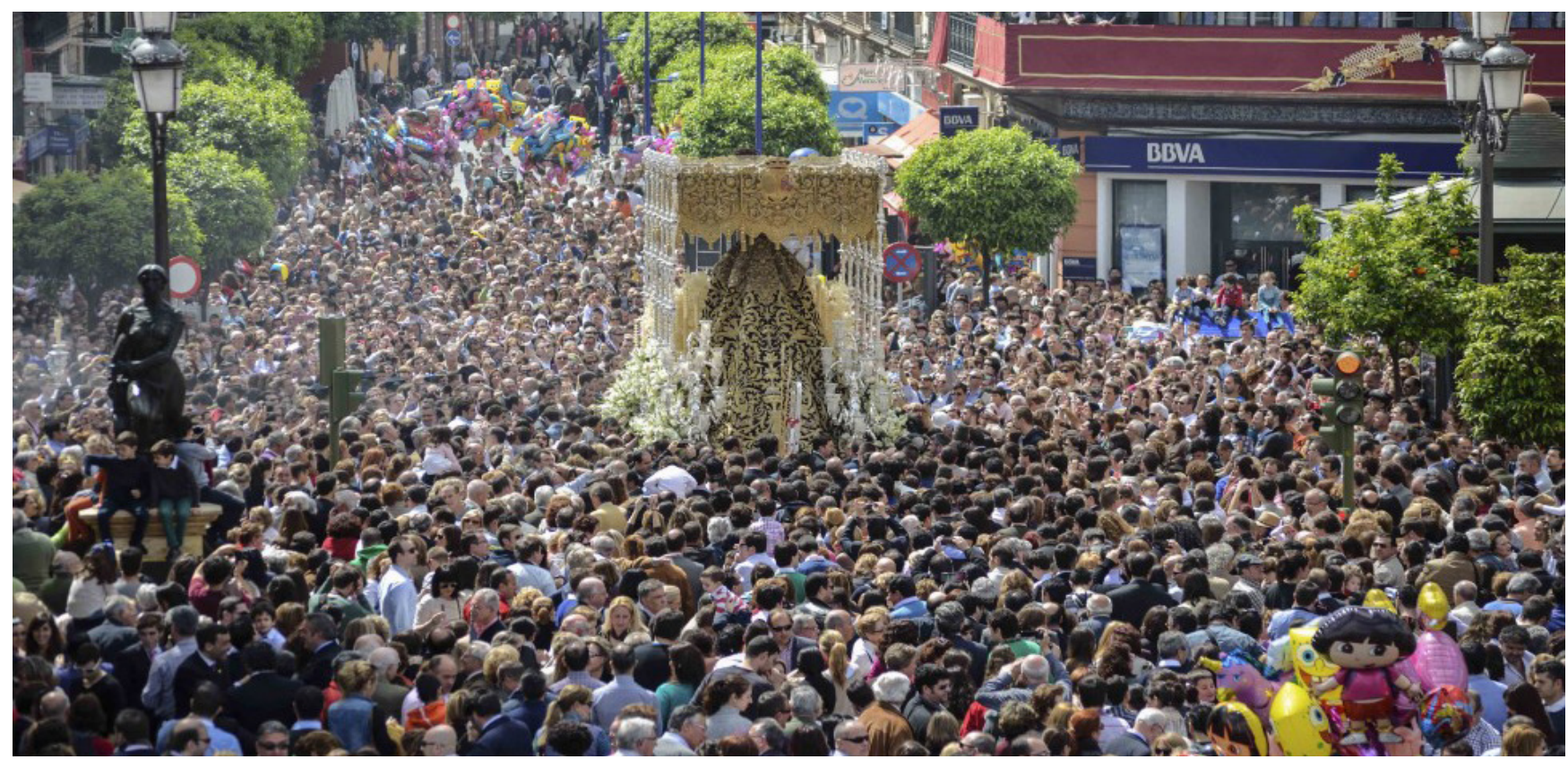

Figura 1.- Aspecto del barrio de Triana durante la Semana Santa del año 2014, en el que se aprecia la masificación de personas atraídas por el exitoso espectáculo religioso y sensitivo que invade Sevilla durante siete días. (Foto: Ismael Pérez) 
Ante el eufórico y exitoso periodo que atraviesa la Semana Santa sevillana desde la segunda mitad del siglo $X X$, se plantea la posibilidad de profundizar en el estudio de fórmulas capaces de orquestar y vertebrar la protección del evento aunando tanto la dimensión material como la inmaterial, así como de las artes y artesanías que en la actualidad siguen manteniendo en vigor los modelos y procedimientos definidos en la Edad Moderna. Es decir, confrontar el desafío de salvaguardar un acontecimiento heredado que, más allá de haber fosilizado sus enseres, continúa elaborando creaciones contemporáneas que también han de ser analizadas y protegidas ante el auge de nuevos encargos inspirados en los modelos más populares. Todo ello desde el respeto y la responsabilidad que implica el estudio in situ, al encontrarnos con bienes materiales cuya naturaleza los mantiene alejados de los cauces habituales de investigación y conservación como son los museos o las universidades y, en consecuencia, de los profesionales de la conservación-restauración, pues adulteraríamos y falsearíamos una realidad que basa gran parte de su trascendencia en su vitalidad y dinamismo. Por tanto, ¿cómo abordar su conservación más allá de la legislación nacional?

\section{El Patrimonio con el Sello Europeo, una oportunidad}

En la actualidad, la consideración de la Semana Santa sevillanacomoCelebracióndelnterésTurísticolnternacional desde 1980 se antoja más que insuficiente a todos los niveles. La solicitud del Senado en el año 2015 de incluir en la Lista del Patrimonio Inmaterial de la Humanidad por la UNESCO a la Semana Santa nacional ${ }^{2}$ supone un gran paso para mejorar la consideración internacional de la fiesta. En la propuesta, resuelta en noviembre de 2015, se pretende acentuar la diversidad de manifestaciones que se dan en el territorio nacional durante el mismo periodo de tiempo y con el mismo objeto. ${ }^{3}$ En este sentido, una de las grandes particularidades de la Semana Santa sevillana radica en su dimensión continental desde prácticamente su génesis, lo que posibilita su alineamiento con otras figuras de protección internacionales como el relativamente reciente Patrimonio con el Sello Europeo.

A modo de resumen, la concesión del Sello Europeo pretende consolidar el sentimiento de pertenencia de los ciudadanos europeos a la Unión mediante la estimulación del diálogo intercultural, sobre todo, a través de políticas culturales y del turismo cultural, para hacer visible los valores democráticos y los derechos humanos en los que se cimienta la integración europea. Con ello se aspira a dotar de un valor añadido a las diferentes manifestaciones que conforman el mosaico cultural europeo, sirviendo de apoyo a otras iniciativas como la mencionada de la UNESCO.

La andadura de esta nueva figura patrimonial comenzaría en el año 2011, promovida precisamente por países como España, ${ }^{4}$ lo que supone todo un gesto por mejorar el conocimiento y la visibilidad en los canales internacionales de los valores comunes en los que se sustentan la historia y la cultura de esta Europa con una identidad mestiza pero común, y en la que ciudades como Sevilla desempeñarían un papel fundamental durante un prolongado periodo de tiempo.

Este interés por despertar una conciencia europea no puede obviar el sentimiento religioso que durante siglos impregnaría toda su geografía y que, más allá de confrontaciones políticas o teológicas, definiría -y en cierta medida uniría- la vida cotidiana y la cultura de la masa popular en la que se insertarían nuestros ancestros, padres del actual continente. Idea que también quedó reflejada en la concesión del Sello por la Unión Europea a los enclaves de "La Reforma" en Alemania y en la presencia de un total de quince lugares galardonados con un preponderante cariz teológico [figura 2], lo que supone casi un $25 \%$ del total de galardones hasta el momento. La fortuna y riqueza de Europa, entendida a través de la diversidad y heterogeneidad de sus pueblos, encuentra un gran testimonio de su realidad religiosa a lo largo de la modernidad en el evento procesional hispalense que sigue celebrándose actualmente.

Es, precisamente, en la vertiente lúdica y sensitiva donde radica gran parte del valor de este patrimonio en nuestro tiempo. Si bien es cierto que la salida en procesión supone una gran manifestación de religiosidad popular durante la estación de penitencia, el sentido cultural de los bienes materiales que dan vida a la fiesta la convierten en un evento fácilmente asimilable para cualquier individuo $y$, además, representativo de la historia occidental para un ciudadano europeo. Todo ello indistintamente del credo que profese, gracias a la dimensión efectista y sensual que alcanza la capital andaluza durante siete días, lo que la sitúa a la altura de eventos como el valorado Misterio

\section{ШAbadía de Cluny}

㷊Acrópolis de Atenas

- Arquitectura religiosa prerrománica: Iglesia de Santa Margarita en Kopcany e Iglesia de San Jorge en Kostol'any por Tribecom

—Catacumbas de Rabat

- Catedral de Braga

+ Catedral de San Pedro en Ginebra

$\square$ Catedral St. Wenceslas y Stanilias en la colina de Wawel en Cracovia

$\checkmark$ Cementerio de Zale en Ljubiana

$\because$ Circuito de seis iglesias con frescos bizantinos y post-bizantinos

- Convento de Jesús en Setubal

- Corte de honor du Palais des Papes d'Avignon

- Iglesia Memorial del Espíritu Santo en Javorca

E Iglesia y colegios calvinistas de Debrecen

E La Reforma

$\square$ Región de los Bosques Sagrados de Zemaitija y Colina de las Cruces

Figura 2.- Lugares y sitios de carácter teológico distinguidos con el Patrimonio con el Sello Europeo (Gráfico: Pablo Travasos) 
de Elche, la celebración de la carrera del Palio en Siena, o la construcción de los enormes castillos de Nola, Palmi, Sassari o Viterbo, todas ellas con la consideración de Patrimonio Cultural Inmaterial de la Humanidad por la UNESCO y grandes muestras del papel sobresaliente de los eventos festivos como nexo de unión entre civilizaciones [figura 3].

Al trascender la primera capa del pomposo ceremonial apreciamos los elementos inmateriales -que no intangibles- que han logrado mantenerse a lo largo de los siglos. Ceremonial que en pleno sigloXXI sigue inspirándose de forma natural en la Edad Moderna, periodo en el que la urbe se erige en la puerta de Europa al Nuevo Mundo al mismo tiempo que recibe el influjo de los principales focos políticos, artísticos, económicos, intelectuales y culturales europeos, desde Bélgica a Italia. Sevilla, en el momento que comienza a gestarse y definirse su mayor evento festivo, es una de las capitales más importantes de un Viejo Continente que también afronta los acontecimientos de la Reforma y la Contrarreforma (Perla 2012: 186). La Semana Santa sevillana es el fiel reflejo de todos estos conceptos y acontecimientos transfronterizos, y de ese espíritu tridentino y contrarreformista, que se han venido refundando desde el siglo XVI a través del desarrollismo de la fiesta hispalense mediante la propia mirada e idiosincrasia local. A través de este prisma aparentemente local pero con un poso continental irrefutable, es como se ha logrado mantener viva la fiesta hasta nuestro tiempo (Sanz 1999: 183).

Si bien es cierto que las particularidades históricoartísticas son fundamentales para demostrar la faceta europeísta del festejo, la contemporaneidad es uno de

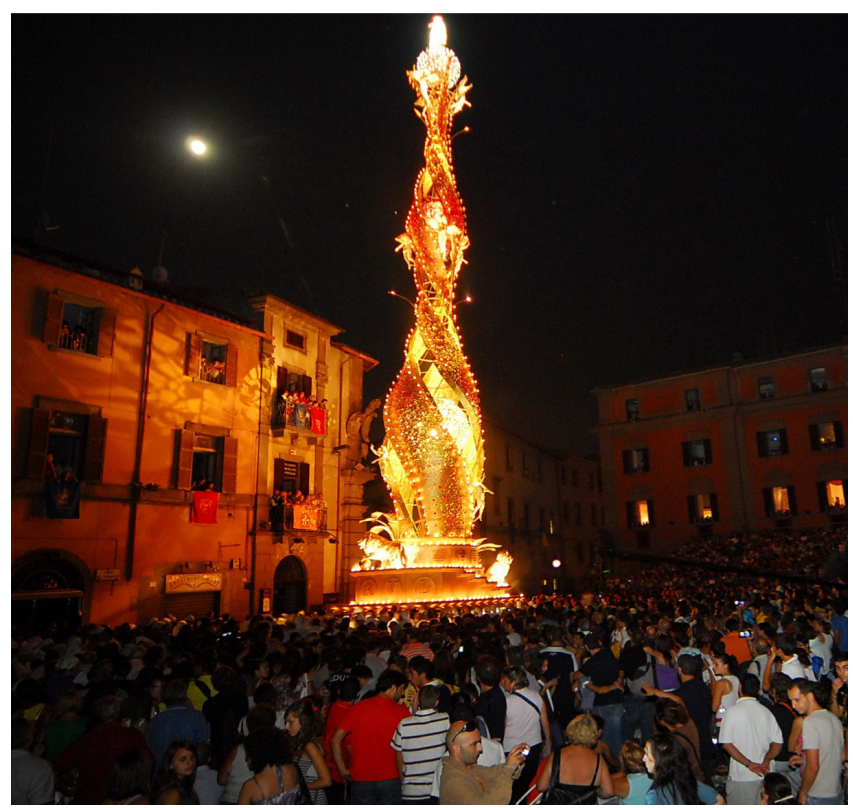

Figura 3.- Efectos lumínicos de la Macchina di Santa Rosa de Viterbo, en línea con la teatralidad de las fiestas de la Europa austral. (Foto: Ayto. Città di Viterbo) sus valores primordiales y uno de los principales objetivos perseguidos por el Sello Europeo para la conservación del patrimonio creado. Éste enfoca sus mayores esfuerzos hacia unas nuevas generaciones y unos jóvenes que aspiran a identificarse con su continente a través de la educación histórica, artística y cultural. Si los actores protagonistas e impulsores del ceremonial son los integrantes de la sociedad, la ampliación del espectro sociológico capaz de comprender e identificarse con él es una de las medidas fundamentales para garantizar la conservación de un patrimonio inmaterial que se traduce en el uso sostenible de los enseres materiales $y$, de este modo, evitar abusos o sustituciones fruto de modas y gustos pasajeros.

Si hasta el momento las diferentes ramas científicas encargadas del estudio de estas manifestaciones humanas hemos ambicionado participar como observadores y transcriptores fidedignos de su dimensión inmaterial, el desbordamiento ocasionado por el éxito de la Semana Santa y su consecuente choque de intereses entre algunos de sus responsables, nos obligan desde hace tiempo a plantear medidas y herramientas eficaces y manejables para favorecer la concienciación de los responsables de su pervivencia. El Patrimonio con el Sello Europeo puede ser una gran oportunidad para ello, pero también para continuar entablando relaciones horizontales entre conservadores, restauradores, y todos aquellos encargados del estudio, análisis y protección del patrimonio, generando diálogos y propuestas de inspiración continental que finalicen con el nudo gordiano en el que parecía haberse convertido la conservación de lo inmaterial hace años.

\section{Revalorización de las Artes y artesanías cofrades}

Es de vital importancia trabajar por evitar la desaparición de los bienes representativos de la presencia humana, tanto a nivel material como inmaterial (Fernández 2012: 283). La conservación de los bienes muebles que conforman la esfera festiva no es suficiente para garantizar su supervivencia futura con un sentido práctico. Y es que, hemos de tener presente, que el deterioro de los bienes no radica únicamente en su estadio físico o material, sino también, y fundamentalmente, en la pérdida de significancia como referente para la sociedad que lo atesora (García 2014: 54).

En este sentido, la labor desempeñada por los numerosos talleres y tiendas hispalenses dedicados al sector cofrade se antoja fundamental a la hora de crear nuevas piezas [figura 4]. Abordar su estudio y apoyo sigue siendo una tarea resbaladiza, sobre todo desde un punto de vista integrador y consciente de sus necesidades actuales, transgrediendo el cariz de atracción turística que en ciertas ocasiones se les quiere otorgar. Tomando como referencia los estudios realizados en Córdoba en relación al impacto económico de la Semana Santa, las hermandades y cofradías invierten al año alrededor de sesenta mil euros en la compra de nuevos enseres. ${ }^{5}$ Esta elevada cifra que se integra en los 


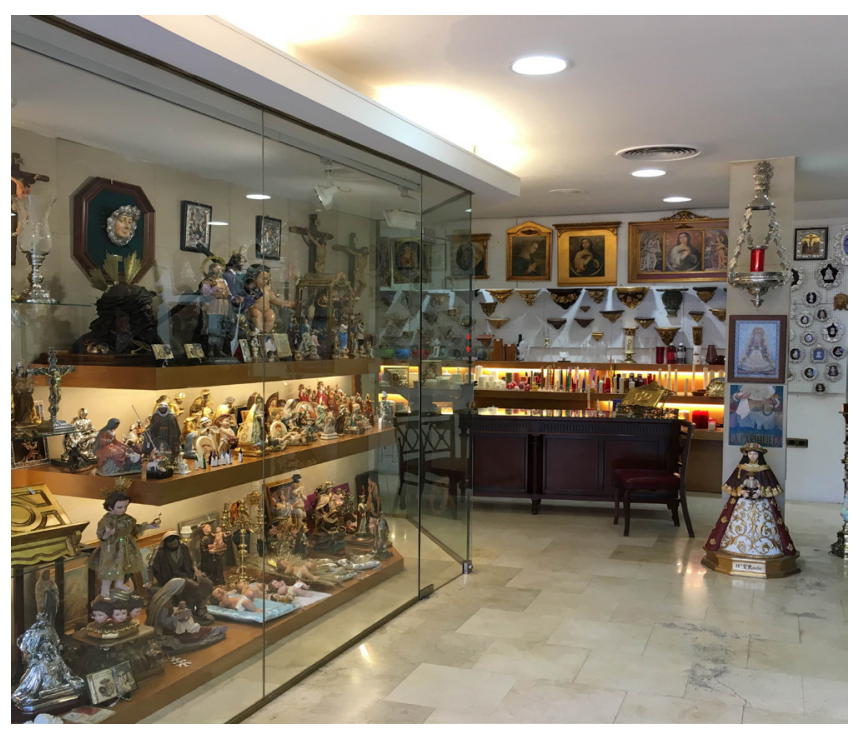

Figura 4.- Ejemplo de tienda cofrade situada en el centro de la ciudad ante la abundante demanda de producto religioso existente. (Foto: Pablo Travasos)

cuarenta y dos millones de euros que genera la ciudad andaluza durante la Semana Santa, aún estaría lejos de los doscientos cuarenta millones de euros (1,2\% del PIB local) que se cifran en Sevilla. ${ }^{6}$ A falta de estudios concretos, la inmensa diferencia entre cifras sirve de referencia para remarcar la importancia económica del sector artesanal en la capital andaluza, lo que demuestra su pujante actividad y la demanda aún existente por parte de las diferentes cofradías y particulares.
No obstante, la crisis económica azota con especial crudeza al sector, obligando a muchos talleres a sobrevivir mediante la venta de algunas obras por un precio inferior a su valor real dado el escaso margen económico con el que muchas hermandades y cofradías también se ven obligadas a negociar. Lentamente el entramado artesanal comienza a recuperar el volumen de facturación, pero recurriendo al mercado exterior alcanzando con sus piezas otras provincias y comunidades. Si bien este efecto diáspora puede ser positivo para el enriquecimiento a todos los niveles de los obradores hispalenses y su provincia, la situación actual revela un claro fracaso administrativo, incapaz de valorar y potenciar una de las canteras de trabajo más importantes de la capital.

En los últimos años, ante la singularidad de las obras fabricadas para la Semana Santa sevillana, se planteó la posibilidad de protegerlas bajo la figura de la "denominación de origen". Sin embargo, el estudio histórico-artístico desde un prisma continental del patrimonio conservado y de las obras contemporáneas, pueden permitir una nueva puesta en valor tanto del patrimonio material como del inmaterial. Siendo conscientes de la presencia de una intelectualidad artística de vocación internacional que vio nacer la festividad basándose en creaciones foráneas y que comenzaría a tomar forma a través del planteamiento de artistas como Juan de Arfe o Francisco Pacheco, vemos cómo la fiesta a lo largo de la Edad Moderna basará su sentido existencial y estético en los ideales que definirán también a Europa (Bray 2010: 15-23) [figura 5].

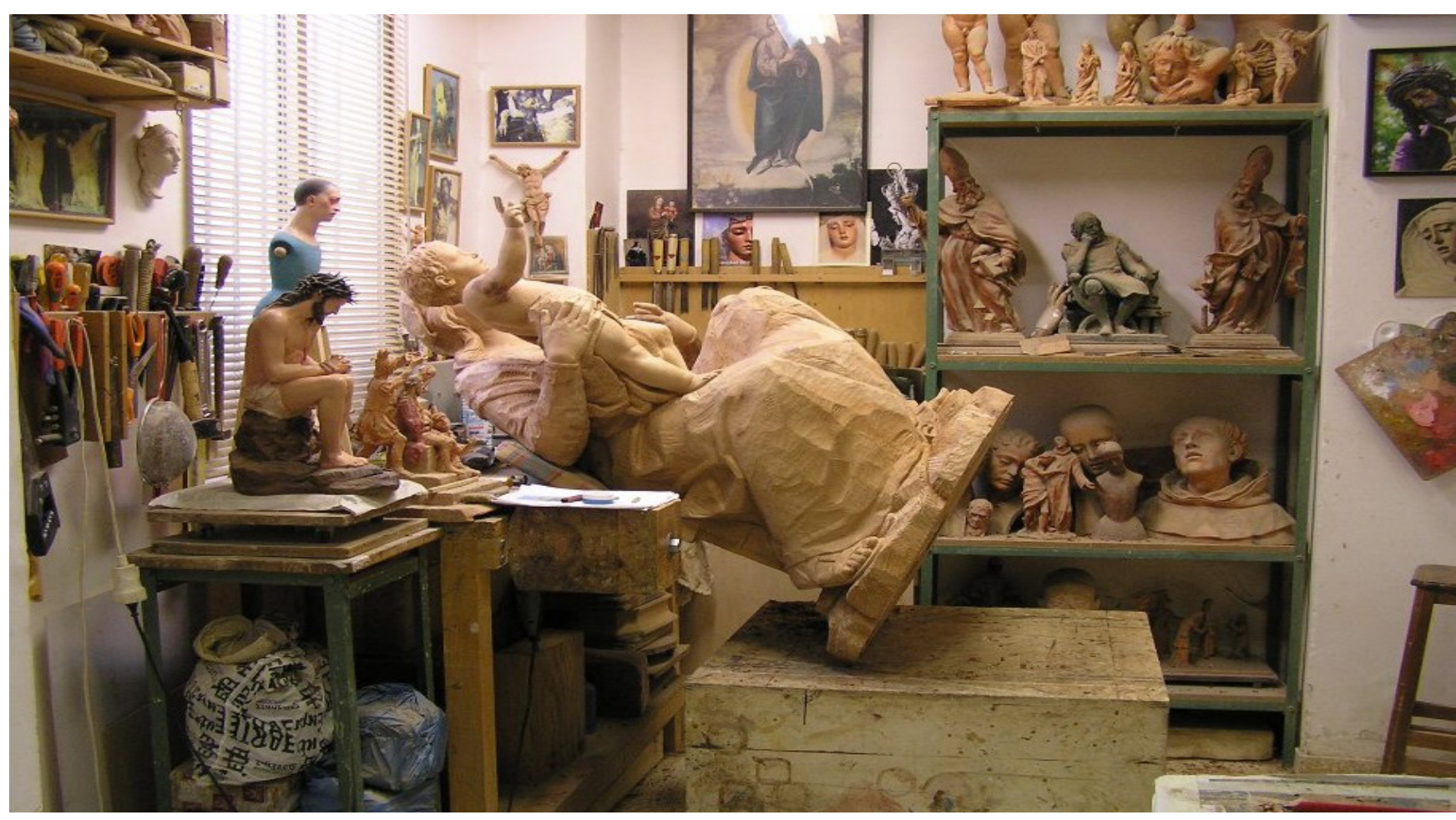

Figura 5.- Taller del imaginero Darío Fernández, continuador de la tradición artística local y heredero del acervo cultural hispalense (Foto: Darío Fernández) 
Las tallas procesionales así como las parihuelas, sus mantos, el exorno floral, la ejecución de bordados, la construcción de varales y el sinfín de elementos que actúan como aderezo en la recreación teatral de la Pasión nazarena y que van desde el olor del incienso y las flores al estruendo de los tambores y cornetas, nos habla de la evolución continua de la Semana Santa y sus protagonistas como reflejo del contexto europeo y de un continuo reverdecimiento tanto social como artístico de las fórmulas e ideales heredados. Y todo ello, gracias en gran parte a unos artistas y artesanos que participan en ella, no solo como genios creadores, sino como hijos de Sevilla y de su sentimiento.

La viabilidad de proyectos capaces de integrar tanto a los talleres de artesanos encargados de crear nuevas obras, así como a los profesionales de la conservaciónrestauración responsables de salvaguardar el patrimonio sacro, y a las asociaciones y agrupaciones comprometidas con mantener vigente el ceremonial, es plausible y notoria. El valor de contemporaneidad que siguen inculcando los talleres y tiendas ante la demanda social existente puede alcanzar un mayor grado de visibilidad y potenciación a través de cauces como el Patrimonio con el Sello Europeo, protegiendo a unos artesanos y a unos conservadoresrestauradores que mantienen viva una forma de trabajar y de vivir el arte de la fiesta que solo puede conservarse a través de la producción en sus talleres. Producción que vería amplificada su repercusión al enlazarse de forma directa con uno de los periodos de calidad artística, creativa y cultural más brillantes de la historia de España y del mundo occidental como es el Siglo de Oro.

Este grado de protección diferenciador favorecería la disminución de sustituciones o destrucción de piezas por gustos y modas incontroladas, como sigue ocurriendo en muchos casos aún hoy día; en tanto en cuanto, el galardón europeo fomenta la divulgación de los actores protagonistas de la cultura europea, situando el acento no en los enseres sino en la dimensión inmaterial que éstos refundan y que desean seguir transmitiendo. Si durante el siglo XX fuimos testigos de cómo gran parte del patrimonio hispalense se dispersaba por diferentes comunidades, las herramientas y el poso de conocimiento adquirido a través de profundas investigaciones científicas durante el siglo XXI nos permiten abordar de forma respetuosa, no invasiva y sostenible la conservación de las expresiones que estructuran una de las conmemoraciones más populares y multitudinarias de España. El fortalecimiento de los pilares continentales existentes en la capital andaluza es indispensable para la evolución y regeneración económica de las artes y artesanías cofrades en estos tiempos de globalización, así como para favorecer la erradicación del intrusismo en las labores del conservador-restaurador mediante la revalorización y emancipación de su figura dentro de talleres autónomos e independientes de grandes centros de conservación y tan diferentes en cuanto a función y deontología profesional de la de los artesanos. Es decir, emplear las escasas herramientas de las que dispone la Administración para demostrar fehacientemente la

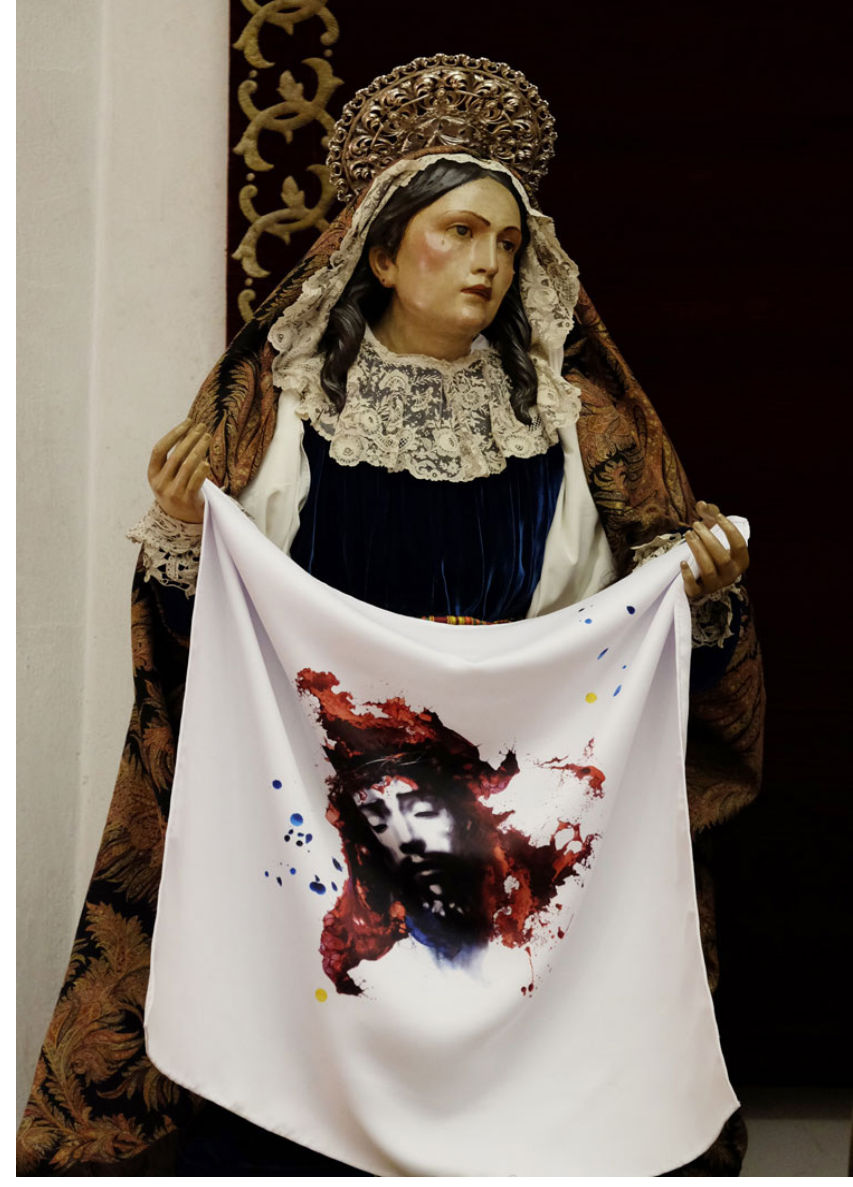

Figura 6.- Paño de Verónica para la Hermandad del Valle, obra del artista Dionisio González, realizada mediante impresión digital en el año 2015. (Foto: Hdad. del Valle)

importante consideración de nuestros actores culturales a través de la inversión para garantizar su supervivencia (Rioja 2006: 88).

\section{Las hermandades y cofradías como fideicomisos}

La orientación de las hermandades y cofradías por parte de expertos en la conservación del patrimonio sigue siendo uno de los grandes obstáculos a la hora de abordar la salvaguarda de la festividad. Los diferentes intentos realizados hasta el momento han logrado aumentar el grado de concienciación por parte de unas hermandades que siguen siendo custodias legítimas de los enseres del festejo, pero no con el calado o la profundidad suficiente como para asegurar una correcta protección a pesar de las pautas marcadas por la Santa Sede (González 2015: 51-53). Es por ello que las labores de difusión y divulgación siguen siendo necesarias para dejar atrás algunos vicios adquiridos con el tiempo y que ha dificultado la presencia de profesionales en las tareas de conservación y restauración de piezas. Profesionales llegados de instituciones que, en ocasiones, han visto criticado su trabajo por no adecuarse a las exigencias de los propietarios de las piezas que en muchos casos desconocen la legislación vigente. 
El disponer de un galardón de dimensión europea puede favorecer una mejora en esta relación entre conservadorrestaurador y propietario, aumentando el grado de conocimiento de la parte segunda y el de legitimidad de intervención del primero. Dejando a un lado el espinoso tema de los criterios de intervención en obras de imaginería procesional, la presencia de agentes externos y ajenos a la festividad que velen por su integridad puede suponer un importante instrumento de persuasión a la hora de realizar intervenciones ambiguas o ajenas a la normativa vigente si se entablan puentes de comunicación beneficiosos para los propietarios actuales. Asimismo, favorecería la dinámica de conservación de enseres además de la adquisición de nuevas piezas a artesanos y artistas, algo que sin duda repercutiría en el prestigio de la hermandad y cofradía como viene ocurriendo con la céntrica Hermandad del Valle y sus paños de Verónica realizados por artistas contemporáneos de primera fila [figura 6].

A pesar de que desde hace años y desde diferentes ámbitos se apunte la necesidad de erigir un museo cofrade, el hecho de que los enseres sigan en manos de sus propietarios originales es algo que también hemos de preocuparnos por proteger y salvaguardar en la medida de nuestras posibilidades. Es cierto que las condiciones de seguridad, estabilidad y conservación que adquirirían las piezas en un entorno estanco como es el museo sería algo idóneo para mantener la dimensión material de las piezas. De hecho, muchas hermandades

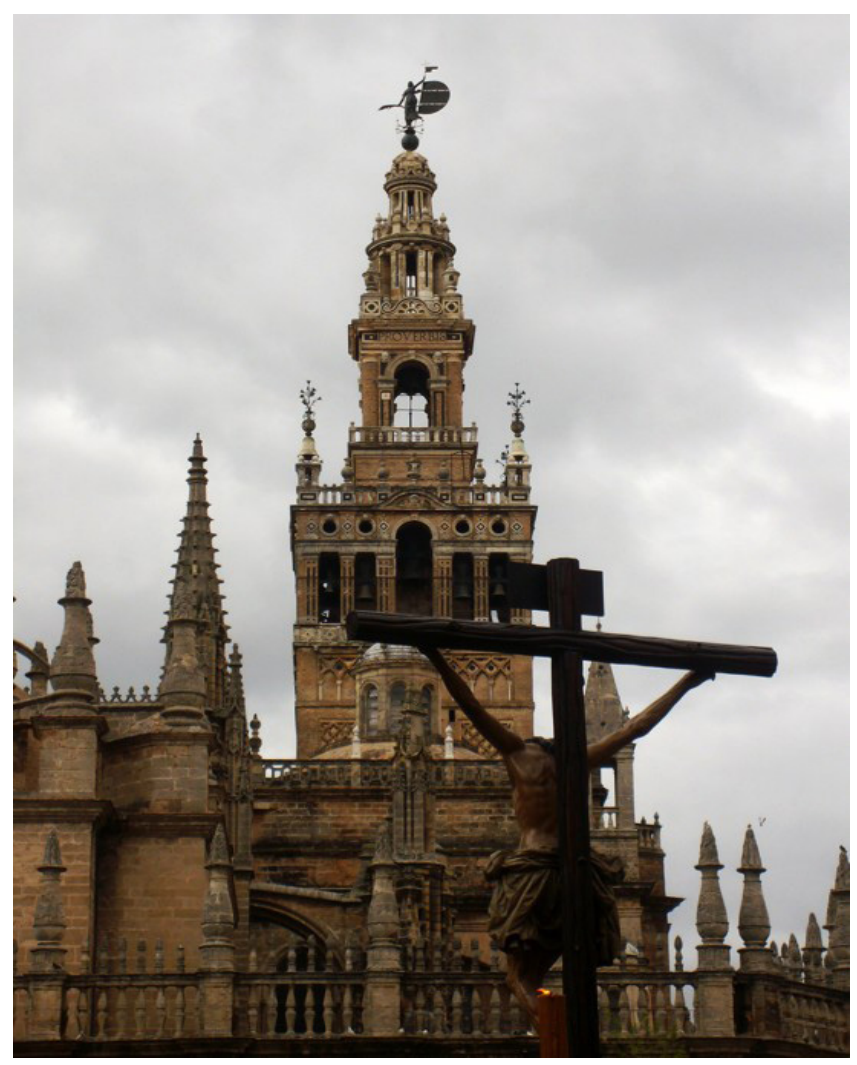

Figura 7.- Santísimo Cristo de la Buena Muerte durante su estación de penitencia a la Catedral de Sevilla en el año 2014 (Foto: M. Auxiliadora Peña) apenas cuentan con espacio suficiente para albergar de forma digna todo su patrimonio. Sin embargo, el uso diario al que están sometidas muchas de estas piezas, así como la relación casi familiar que mantiene el pueblo con muchas de las obras, podría favorecer un desequilibrio en la estima de las piezas por realizar tareas que, más allá de ser preventivas, podrían entenderse como de intervención o en el extremo como intromisión. La Semana Santa sevillana, a diferencia del exitoso modelo conservativo que se practica en Valladolid (Álvarez 2012: 99-117), no es un museo que salga a la calle, sino una realidad viva, palpitante durante todo el año. ${ }^{8}$

Con la concesión del Sello Europeo se debe abordar la importancia de estas cofradías en el mantenimiento del festejo, no sólo a través de la trasmisión y mantenimiento de las piezas materiales, sino de los valores de caridad, solidaridad, humanidad y cristiandad que aún mantienen tras centenares de años. En definitiva, de los inmateriales. Ellas son las responsables primeras y las protagonistas de una actividad cuyo origen pastoral ha permitido que aún hoy día disfrutemos de un patrimonio que por derecho les pertenece, pero que hemos de salvaguardar todos los europeos. Lo que supone, de nuevo, un hecho diferenciador y que, lejos de pretender exclusivamente musealizarlo, hemos de intentar conservar incólume a través de medidas de difusión y puesta en valor.

La importancia de permanencia de los enseres en la ubicación para la que fueron creados no se corresponde con una voluntad retrógrada o romántica, sino pragmática y utilitaria a diferentes niveles. La localización de los inmuebles sevillanos situados en su centro histórico tiene un papel fundamental en la concepción urbanística sevillana y, sobre todo, en la creación de los itinerarios para afrontar el recorrido durante la estación de penitencia. La intencionalidad sacralizadora perseguida con la ordenación urbana durante siglos se ha logrado mantener en cierto sentido (Domínguez 2003: 370), de tal modo, que en la actualidad prácticamente el $90 \%$ de los inmuebles protegidos por su valor patrimonial se contextualizan en la Edad Moderna. Todo ello nos invita nuevamente a componer nuestra solicitud para el Sello Europeo considerando valores como la relación espacial existente entre los diferentes conventos, iglesias, parroquias... medio en el que los bienes adquieren todo su sentido durante la estación de penitencia.

El abordaje del centro de Sevilla que durante una semana realizan las cofradías y sus hermanos para alcanzar la Catedral permite al resto de la ciudadanía y a sus visitantes participar de manera activa en un auténtico evento artístico que casi puede entenderse como una performance, y en la que cualquier persona se ve desbordada tanto por la calidad material como por la imponente corpulencia que alcanzan los olores de la ciudad en primavera, los sonidos del pueblo en forma de vítores o saetas, los colores proyectados por la luz del día y los cirios de noche, etcétera. En definitiva, todo un espectáculo barroco vigente en pleno siglo XXI que devuelve el sentido original a los inmuebles cristianos de la ciudad [figura 7]. 
Del mismo modo, el análisis y sustento de estos itinerarios desde un punto de vista sociocultural permitiría a las administraciones emprender las medidas necesarias para garantizar la sostenibilidad del acontecimiento, sin menoscabo de la seguridad colectiva de una fiesta que comienza a dar muestras de incapacidad de autogestión ante la ingente cantidad de personas que la visitan cada año. En definitiva, establecer prioridades que definan el papel de las hermandades y cofradías como fideicomisos de un patrimonio que han de custodiar, pero cuyo cuidado ha de compartir.

\section{Conclusión: La fiesta, fuente y caudal}

Basándonos en esta línea, y sin entrar en confrontación con la necesaria inclusión en la Lista del Patrimonio Inmaterial de la UNESCO, la nueva figura de conservación internacional Patrimonio con el Sello Europeo ofrece interesantes posibilidades para aumentar el grado de protección tanto del patrimonio heredado como del contemporáneo.

La confluencia de modelos artísticos flamencos e italianos, unidos a los valores humanistas que evolucionaron durante el barroco sevillano, provocarían que, tras la celebración del Concilio de Trento, las imágenes creadas tuvieran vocación universal, destinadas para cualquier ser humano, mediante la evocación de sus sentimientos más viscerales. No podemos más que maravillarnos e intentar conservar un patrimonio que, a diferencia del que se conserva en los museos, se mantiene contextualizado manifestándose en todo su esplendor cada año gracias a la continua labor de unos vecinos que ya no se encuentran focalizados únicamente en la localidad sevillana, sino que a través de la inserción de sus manifestaciones en la globalidad ha logrado que cada año peregrinen hasta la Catedral habitantes de todo el mundo.

Esto nos habla de un acontecimiento que ejemplifica uno de los principales objetivos a perseguir con el Patrimonio de Sello Europeo, el del diálogo intercultural. La transfiguración del evento religioso en una celebración estética y sensual, permite la evolución también de su consideración social transformándola en un evento de masas en el que se pueda integrar cualquier ciudadano, sobre todo occidental. De este modo, la fastuosidad visual, olfativa y acústica que invade Sevilla durante siete días permitirá a un ciudadano griego excitarse al contemplar la pompa festiva del mismo modo que un protestante, aunque sin llegar a las cotas de integración confesional del practicante católico, quien asiste a la perpetuación de una concepción teológica heredada desde el medievo.

En conclusión, la protección por parte de la Unión Europea de la Semana Santa sevillana permitiría generar nuevas trayectorias de desarrollo, investigación y conservación de los agentes integrantes a través del establecimiento de relaciones y conexiones entre todos ellos. El Patrimonio con el Sello Europeo, en definitiva, ofrece la posibilidad de afrontar la salvaguarda de la fiesta como lo que realmente sigue siendo en la actualidad: fuente y caudal de riqueza cultural. Es nuestra responsabilidad favorecer el mantenimiento de ese flujo del que también han de beber las generaciones futuras si lo desean.

\section{Notas}

[1] El proyecto Andalucía Barroca se concibió desde una perspectiva totalizadora e interdisciplinar. Bajo su lema se celebró el congreso internacional y desarrollaron una serie de acontecimientos del máximo interés científico y divulgativo: seis exposiciones monográficas y una itinerante; gran número de actividades de conservación, tanto de edificios como de bienes muebles; la recuperación de la organería barroca más significativa; visitas guiadas en el marco de las Jornadas Europeas del Patrimonio del 2007; documentales de televisión y audiovisuales didácticos; además de otras actividades culturales, como conciertos y conferencias.

[2] En marzo del año 2015 todos los grupos del Senado apoyaron la inclusión de la Semana Santa en la lista representativa del Patrimonio Cultural Inmaterial de la Humanidad de la UNESCO debido a la cantidad de manifestaciones culturales, religiosas y populares que se concentran en la "infinidad de objetos de especial valor artístico, obra escultórica y otros bienes materiales" del Patrimonio Histórico que deben ser en igual medida "protegidos por los poderes públicos con una acción positiva".

[3] El lunes 23 de noviembre de 2015 se afronta la salvaguarda de la Semana Santa como Patrimonio Cultural Inmaterial, dejando constancia de que "esta manifestación encuentra en el país múltiple variables. Es, por tanto, un fenómeno plural que, aun compartiendo rasgos esenciales a lo largo de la geografía española, no permite establecer modelos de fiesta." https://www. boe.es/boe/dias/2015/11/23/pdfs/BOE-A-2015-12647.pdf [consulta 8/3/2016]

[4] En mayo de 2005, el Ministro francés de Cultura y Comunicación a la sazón lanzó la idea en París. España respondió con entusiasmo; tanto que en abril de 2006 firmó en Granada un acuerdo preliminar con Francia y Hungría. Fueron adhiriendo voluntariamente otros Estados a las discusiones preparatorias, hasta que en enero de 2007 tuvo lugar en Madrid la reunión que sentó las bases sólidas de una iniciativa intergubernamental sobre el Sello de Patrimonio Europeo. http://www.mecd.gob.es/mecd/cultura-mecd/areas-cultura/ patrimonio/mc/patrimonioeur/sello-de-patrimonioeur/ historico/presentacion.html [consulta 8/3/2016]

[5] El estudio titulado El impacto económico de la Semana Santa de Córdoba supone todo un hito y un referente a la hora de abordar el análisis real de la fiesta en su contexto más inmediato, aportando también interesantes índices de popularidad y proyección mediática basados en las metodologías planteadas por E.S.I. de la Universidad de Navarra. http://www. economiaandaluza.es/sites/default/files/5.El\%20impacto\%20 
econ $\%$ C3\%B3mico $\% 20$ de $\% 201$ a $\% 20$ Semana $\% 20$ Santa $\% 20$ de\%20C\%C3\%B3rdoba.pdf [consulta 8/3/2016]

[6] Recientemente se está trabajando en el análisis económico real de la fiesta de la Semana Santa, especialmente en Andalucía, para su vertebración como punta de lanza del turismo de masas en ciudades como Sevilla. En esta línea, en la capital andaluza la repercusión se traduciría en una cifra cercana a los doscientos cuarenta millones de euros, frente a los cuarenta y dos millones de euros en Córdoba, o los veinticuatro millones de euros en Málaga. Cifras que superan con creces los dos millones de euros que se generan en ciudades con gran tradición cultural cofradiera como Valladolid o Palencia.

[7] Juan Espadas Cejas, alcalde de Sevilla, realizó una propuesta informal ante los medios de comunicación en febrero de 2015 para alcanzar el sello con denominación de origen, así como la creación de un espacio de muestra permanente de las obras artesanales sacras, con la intención de convertirlas en un "atractivo turístico [...] impulsando su labor y frenando la huida de talleres fuera de la ciudad". http://sevilla.abc.es/ pasionensevilla/actualidad/noticias/espadas-propone-unasede-expositiva-y-una-denominacion-de-origen-para-el-artesacro-69182-1422898855.html [consulta 8/3/2016]

[8] La inestimable labor del Museo Nacional de Escultura de Valladolid así como de la Escuela de Arte y Superior de Conservación y Restauración de Bienes Culturales de Valladolid aún se encuentra lejos de la realidad hispalense, donde los análisis in situ siguen siendo casos aislados como el de la Virgen del Rosario de la Hermandad de Montesión http://elcorreoweb. es/maspasion/el-microclima-de-un-paso-de-palio-CY1450859 [consulta 8/3/2016]

\section{Bibliografía}

ÁLVAREZ VICENTE, A. (2015). "La conservación preventiva de la escultura procesional". En El conservador-restaurador de patrimonio cultural: la conservación preventiva de la obra de arte, Martínez Montero, J. y Santos de Paz, L., (coord.). León: Universidad de León, 99-117.

BRAY, X. (2010). "Lo sagrado hecho real. Pintura y escultura española (1600-1700)". En Lo sagrado hecho real. Pintura y escultura (1600-1700), Bray, X. (coord.) Madrid: Ministerio de Cultura, 15-43.

CARMONA RODRÍGUEZ, M. (1993). Un siglo de música procesional en Sevilla y Andalucía. Sevilla: Servigraf.

CARRERA DÍAZ, G. (2009). "Atlas del Patrimonio Inmaterial de Andalucía: puntos de partida, objetivos y criterios técnicos y metodológicos". PH: Boletín del Instituto Andaluz del Patrimonio Histórico, 71: 19-41.

CARRERA, J. (1998) La acción cultural de la Comunidad Europea. Madrid: Aranzadi.
COLLANTES DE TERÁN, A., (2014). "Sevilla en el sistema urbano de la Andalucía bajomedieval". Edad Media, 15: 76-96.

CONSEJO DE LA UNIÓN EUROPEA (2002). Textos relativos al ámbito de la cultura a nivel de la Unión Europea: 19982001. Luxemburgo: Oficina de publicaciones oficiales de las Comunidades Europeas.

DE VICENTEY RODRÍGUEZ, J. F. (2006). “El patrimonio eclesiástico. Los museos eclesiales: modos de organizaciones". Museo 11, 4755.

DOMíNGUEZ BERENJENO, E. L. (2003). Teoría y práctica de la crítica historiográfica: transformaciones socioproductivas $y$ procesos urbanos en Isbilia-Sevilla (ss. XI-XIII). Sevilla: Universidad de Sevilla.

FERNÁNDEZ DE PAZ, E. (2012). Las actividades artesanas en Andalucía: economía y cultura del trabajo manual. En Expresiones culturales andaluzas Moreno Navarro, I., y Agudo Torrico, J. (coord.). Sevilla: Aconcagua libros, 283-318.

GARCÍA FERNÁNDEZ, I. (2014). La conservación preventiva de bienes culturales. Madrid: Alianza Forma.

GILA MEDINA, L. (coord.)(2013) La consolidación del barroco en la escultura andaluza e hispanoamericana. Granada: Universidad de Granada.

GONZÁLEZ GÓMEZ, J.M. y RODA PEÑA, J. (1992) Imaginería procesional de la Semana Santa de Sevilla. Sevilla, Universidad de Sevilla.

GONZÁLEZ LÓPEZ, M. J. (2015). "Análisis de los criterios de intervención en Bienes Eclesiásticos". En Ge-conservación, 7: 5059.

LLOP I BAYO, F. (2009). “Un patrimonio para una comunidad: estrategias para la protección social del Patrimonio Inmaterial". Patrimonio Cultural de España, 0: 133-144.

OFFICIAL JOURNAL OF THE EUROPEAN HERITAGE (2011). Decision No 1194/2011/EU of the European Parliament and of the Council of 16 November 2011 establishing a European Union action for the European Heritage Label. Brussels: European Parliament.

PÉREZ BUSTAMANTE, D.C. (2011). La política cultural de la Unión Europea. Madrid: Dikyson.

PÉREZ MULET, F. (2008). La imagen reflejada. Andalucía espejo de Europa. Cádiz, Junta de Andalucía.

PERLA DE LAS PARRAS, A. (2012). “La escuela andaluza: Granada y Sevilla". En Arte y Realidad en el barroco I, Soto Caba, M.V. (coord.), Madrid: Centro Ramón Areces, 185-206.

PIJOÁN, J. (2000). Arte barroco en Francia, Italia y Alemania: siglos XVII-XVIII. Madrid: Espasa-Calpe. 
RIOJA LÓPEZ, C. (2006). “Artesanía y administración. Encuentros y desencuentros", $\mathrm{PH}$ : Boletín del Instituto Andaluz del Patrimonio Histórico, 59: 76-85.

RODRÍGUEZ DOMINGO, J. M. (2010). “El patrimonio cultural de la iglesia católica en España: treinta años de legislación (1979/2009)". En La protección del patrimonio histórico en la España demócrata, Henares Cuéllar, I. L. (coord.), Granada: Universidad de Granada, 481-506.

SANZ SERRANO, M. J. (1999). "Las artes ornamentales en las cofradías de la Semana Santa sevillana". En Las cofradías de Sevilla: historia, antropología y arte, Sánchez Guerrero, J. (coord.) Sevilla: Universidad de Sevilla, 153-184.

SASTRE ZAMORA, Á., (2012). Estudio sobre la conservación preventiva de los pasos procesionales históricos de la Semana Santa vallisoletana. Valencia: Universidad Politécnica de Valencia.

TRAVASOS HERNÁNDEZ, P. (2015). La Semana Santa sevillana: Patrimonio con el Sello Europeo. Tesina s. p.

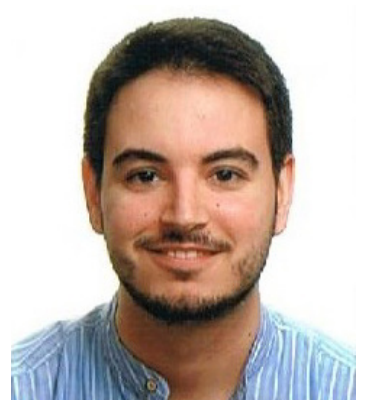

\section{Pablo Travasos Hernández}

pablotravasos@gmail.com

Graduado en Conservación y Restauración de Bienes Culturales (2014) por la Universidad de Sevilla (US) y magíster en Estudios Avanzados de Historia del Arte Español (2015) por la Universidad Complutense de Madrid (UCM) especializado en la Edad Moderna. Tras una estancia en el Museo Benaki de Atenas (2014) se embarca en el ámbito de la investigación cultural y patrimonial aportando una visión interdisciplinar e internacional. Actualmente continua con sus tareas como investigador y conservador del patrimonio cultural y desarrollando el proyecto Semana Santa Europea. 